\title{
Innovations in Ground and Airborne Technologies as Reference and for Training and Validation: Terrestrial Laser Scanning (TLS)
}

\author{
M. Disney ${ }^{1,2}$ (D) A. Burt ${ }^{1} \cdot$ K. Calders ${ }^{3} \cdot$ C. Schaaf $^{4} \cdot$ A. Stovall $^{5}$
}

Received: 10 September 2018 / Accepted: 14 February 2019 / Published online: 29 March 2019

(c) The Author(s) 2019

\begin{abstract}
The use of terrestrial laser scanning (TLS) to provide accurate estimates of 3D forest canopy structure and above-ground biomass (AGB) has developed rapidly. Here, we provide an overview of the state of the art in using TLS for estimating forest structure for AGB. We provide a general overview of TLS methods and then outline the advantages and limitations of TLS for estimating AGB. We discuss the specific type of measurements that TLS can provide, tools and methods that have been developed for turning TLS point clouds into quantifiable metrics of tree size and volume, as well as some of the challenges to improving these measurements. We discuss the role of TLS for enabling accurate calibration and validation (cal/val) of Earth observation (EO)-derived estimates of AGB from spaceborne lidar and RADAR missions. We give examples of the types of TLS equipment that are in use and how these might develop in future, and we show examples of where TLS has already been applied to measuring AGB in the tropics in particular. Comparing TLS with harvested AGB shows $r^{2}>0.95$ for all studies thus far, with absolute agreement to within $10 \%$ at the individual tree level for all trees and to within $2 \%$ in the majority of cases. Current limitations to the uptake of TLS include the capital cost of some TLS equipment, processing complexity and the relatively small coverage that is possible. We argue that combining TLS measurements with the existing ground-based survey approaches will allow improved allometric models and better cal/val, resulting in improved regional and global estimates of AGB from space, with better-characterised, lower uncertainties. The development of new, improved equipment and methods will accelerate this process and make TLS more accessible.
\end{abstract}

Keywords Terrestrial lidar $\cdot 3 \mathrm{D}$ forest structure $\cdot$ Forest structure $\cdot$ Above-ground biomass $\cdot$ Biomass

M. Disney

mathias.disney@ucl.ac.uk

Extended author information available on the last page of the article 
Fig. 1 Point clouds from three contrasting forests (all collected using a Riegl VZ-400 TLS) and detail of a single tree and branch. In the plot cases, 1 ha is shown either oblique or in elevation and the point clouds of individual trees are shown in different colours. Top row: from Calders et al. (2018), a 1 ha section of deciduous woodland, Wytham Woods, UK, containing 559 trees (232 with diameter-at-breastheight $(\mathrm{DBH})>0.2 \mathrm{~m})$; second row: moist tropical forest at Caxiuanã, Brazil, showing 151 trees with $\mathrm{DBH}>0.2 \mathrm{~m}$; third row: moist tropical forest at Lopé, Gabon, with 107 trees of DBH>0.2 m; bottom row, left panel: single tree from Caxiuanã $(H=30 \mathrm{~m}, \mathrm{DBH}=0.65 \mathrm{~m})$; bottom row, right panel: $\sim 1.5 \mathrm{~m}$ section of left-most branch, showing resolution of branches of $<4 \mathrm{~cm}$ diameter. These trees are the result of processing the raw plot TLS data to extract only the points for each tree, to remove all other points, i.e. understory and trees with $\mathrm{DBH}<0.2 \mathrm{~m}$ and to remove any topographic variations

\section{Introduction}

Terrestrial laser scanning (TLS) is a relatively new technology, developed since the early 2000s for surveying applications, i.e. for measuring very precise distances and angles. TLS works by using laser pulses to measure distance and 3D $(x, y, z)$ location to within $\mathrm{mm}$ potentially over hundreds of metres. TLS has largely been developed in its current form by commercial instrument developers such as RIEGL (http://www.riegl.com/), Leica Geosystems (https://leica-geosystems.com/en-gb), Faro (https://www.faro.com/), Zoller and Fröhlich (https://www.zf-laser.com/Home.91.0.html?\&L=1) and others. The utility of TLS for measuring tree properties was explored in the early 1990s by the forestry community, particularly for providing new ways to measure properties already measured for forest surveying. These include tree height, diameter-at-breast-height (DBH), crown size and basal area. However, while TLS has proved useful for these applications (Hopkinson et al. 2004; Calders et al. 2015; Newnham et al. 2015), it is the potential to provide $\mathrm{cm}$ and even mm-accurate 3D structural detail (albeit at the individual branch, rather than plot scale), particularly for estimating 3D full-tree volume, and from this above-ground biomass (AGB), that has seen a rapid increase in interest in TLS for measurement of AGB. There is particular interest in how these measurements can be used in support of spaceborne Earth observation (EO) estimates of AGB, from new laser and RADAR missions, particularly via calibration and validation. The capability of TLS has also been extended to the spectral domain, via research-led development of multi- and even hyperspectral lidar instruments (Danson et al. 2014; Hakala et al. 2012; Douglas et al. 2015). Figure 1 shows an example of the 3D information provided by TLS, in this case TLS point clouds from deciduous broadleaf woodland in the UK (Calders et al. 2018) and tropical forests in Brazil and Gabon (Burt 2017).

The importance of AGB and forest structure more generally has driven the development of spaceborne EO missions targeting these properties (GCOS 2010). Estimating AGB accurately and consistently on regional to global scales is critical for reducing current uncertainties in carbon stocks and deforestation fluxes, which differ in magnitude but also location (Saatchi et al. 2011; Harris et al. 2012; Baccini et al. 2012;). Some of these uncertainties arise from observation and methodological differences (Avitabile et al. 2016) as well as in assumptions of wood density $\rho$ (Mitchard et al. 2013, 2014), but there is also considerable uncertainty in the upscaling of spatial estimates and magnitude as well. New EO missions can reduce these uncertainties, but to fulfil their mission requirements in terms of both accuracy and precision will depend on accurate and independent groundbased estimates of AGB to calibrate EO retrieval methods and validate the resulting products. The difficulty of measuring AGB manually via forestry methods means that it is challenging to obtain validation data; TLS is one way to address this gap (Stovall and Shugart 2018). The Committee on Earth Observation Satellites (CEOS) has identified TLS as a key 

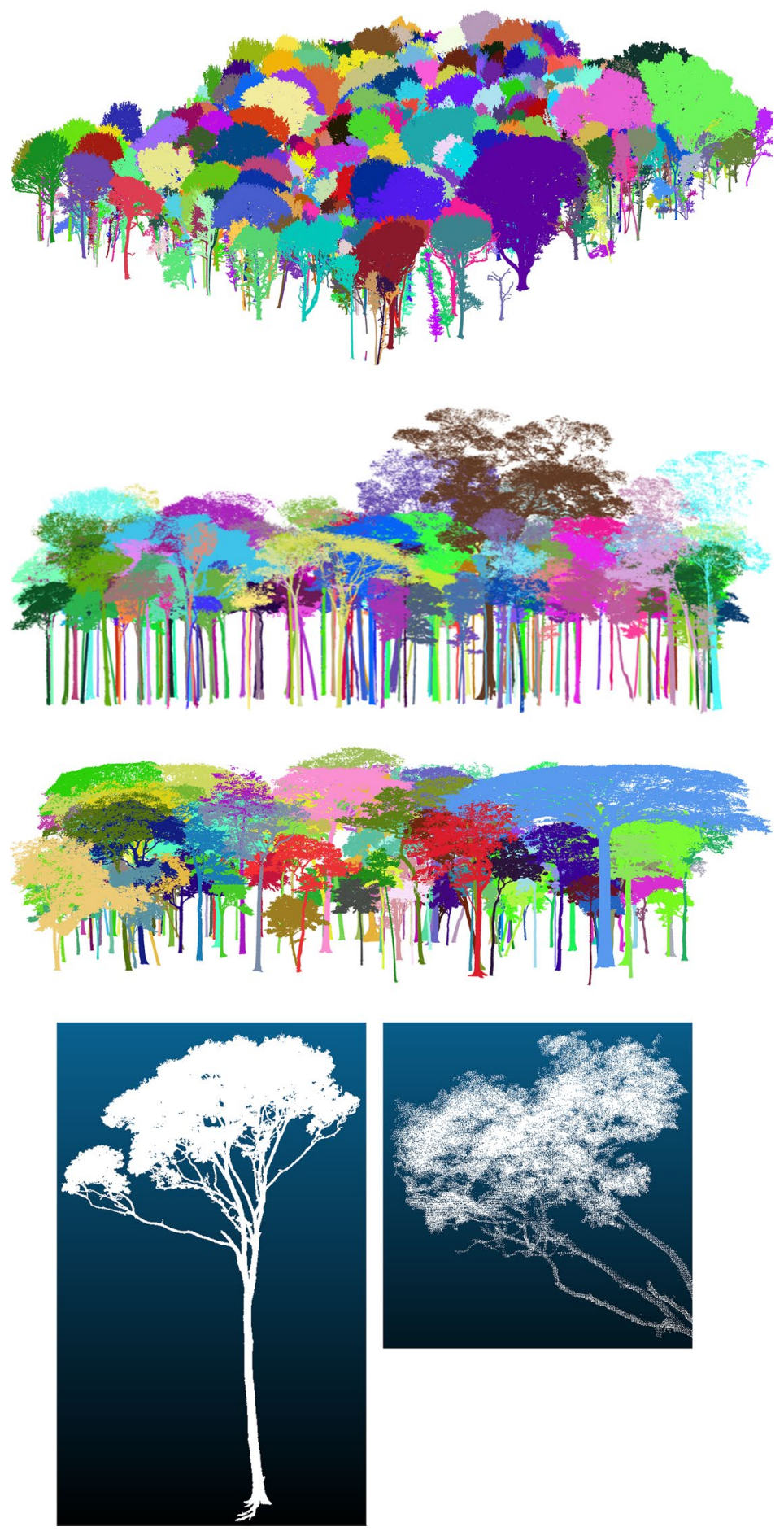
approach to providing accurate calibration and validation data for EO-derived AGB (CEOS LPV WGCV Biomass 2019). Here, we summarise developments in TLS for AGB estimation in support of EO retrievals.

\section{Above-Ground Biomass (AGB)}

Estimating above- and belowground (root) biomass of a tree directly requires careful harvesting and weighing. This is destructive and difficult, particularly for anything other than 'small' trees, e.g., trees with diameter-at-breast-height $\mathrm{DBH}<30 \mathrm{~cm}$ and height, $H<30 \mathrm{~m}$. As such, destructive harvesting is done infrequently, tends to focus on smaller trees in more easily accessible areas, and of course precludes repeat measurements to capture dynamics. And yet spatial estimates of AGB are almost entirely based on extrapolating the masses of these harvested trees, using empirical size-to-mass allometric scaling equations (ASEs) (Baskerville 1972; Brown and Lugo 1984; Chave et al. 2005). The wide use of ASEs is a consequence of their reliance on only simple, rapid measurements, as well as being the only way we have to extrapolate estimates of AGB spatially. ASEs typically take the form $A G B=a\left(D^{2} H \rho\right)^{b}$, where $D$ and $H$ are DBH and height, respectively, $\rho$ is the wood density $\left(\mathrm{g} / \mathrm{cm}^{3}\right)$, and $a, b$ are empirically derived constants (Feldpausch et al. 2010; Chave et al. 2014). This ASE approach broadly represents a tree as a tapered cylindrical volume. Coefficients $a, b$ can be derived via destructive sampling, and assuming a density $\rho$, AGB can then be estimated. However, the purely empirical nature of the ASE approach means a wide range of slightly different model forms and parameters have been developed, for site- and species-specific or more general regional versions, with often little to distinguish them in terms of suitability, particularly for upscaling (Ahmed et al. 2013). Further, the small sample of destructive harvests on which ASEs are based means that uncertainties in upscaled AGB is potentially large and hard to quantify (Ketterings et al. 2001; Sileshi 2014; Duncanson et al. 2015). As an example, the most comprehensive pan-tropical ASE yet developed is that of Chave et al. (2014) which contains around 4000 destructively harvested trees, only around $10 \%$ of which have $\mathrm{DBH}>70 \mathrm{~cm}$ and/or height, $H>30 \mathrm{~m}$. To estimate pan-tropical AGB, this sample is extrapolated across the hyperdiverse tropics (Ter Steege et al. 2013), containing an estimated 1.4 tn $\left(1.4 \times 10^{12}\right)$ trees of 46,500 species (Pan et al. 2011; Lewis et al. 2013; Crowther et al. 2015; Slik et al. 2015). Other ASEs contain far fewer samples, typically a few dozen in the case of most locally calibrated models (Stovall et al. 2018).

\section{Uncertainty}

Uncertainty is used here to mean the mismatch between an estimate of AGB and the true but unknown value, and can be described by a probability density function (PDF) characterising the range and likelihood of possible values (IPCC 2006). Uncertainty in AGB estimates arises from various sources (Chave et al. 2004; Réjou-Méchain et al. 2017). Firstly, the form and appropriateness of ASE will impact resulting AGB estimates (Molto et al. 2013; Burt et al. 2018). The fundamental ability (or otherwise) of a simple regression equation to represent tree volume and hence AGB, across regions and biomes, is limited. Estimating uncertainty due to model form is also hard in the face of small samples of destructively harvested and weighed trees, particularly as these are potentially biased to smaller 
trees (Ahmed et al. 2013; Sheil et al. 2016; Burt et al. 2018). Lutz et al. (2018) show that across a wide range of forests, the largest $1 \%$ of all trees with $\mathrm{DBH}>1 \mathrm{~cm}$ comprise $50 \%$ of total live tree AGB overall, with trees of $D \geq 0.6 \mathrm{~m}$ comprising $41 \%$ of total AGB. This disproportionate partitioning of AGB in large trees leads to potentially large uncertainties in AGB derived from ASEs with few large trees. This is further compounded by the fact that bigger trees have fundamentally greater variance in AGB (Mascaro et al. 2011; Clark and Kellner 2012). As a result, uncertainty in ASE-derived AGB grows rapidly with DBH.

Wood density, $\rho$, is another major source of uncertainty in estimating AGB using allometry (Niklas 1993; Chave et al. 2006; Swenson and Enquist 2007; Mitchard et al. 2013). The choice of $\rho$ is what translates the ASE-derived volume to mass, but $\rho$ is highly variable within individual trees radially and with height, let alone within and between species and across regions (Chave et al. 2006; Swenson and Enquist 2007). Databases of wood density do exist, but are still limited given the diversity observed in practice (Chave et al. 2009; Zanne et al. 2009; Momo et al. 2018).

A further fundamental issue is that all estimates other than destructive harvests are indirect, leading to the so-called fallacy of misplaced concreteness, i.e. indirect estimates of AGB are not measurements (Clark and Kellner 2012; Sileshi 2014). The problem is that if ground-based estimates of AGB, derived from plot-scale DBH measurements upscaled via ASEs, are used to 'validate' EO-derived estimates of AGB based on H to DBH ASEs, then the resulting spatial estimates (regional, pan-tropical, etc.) will have these uncertainties potentially exacerbated due to the upscaling process (Hill et al. 2013; Sileshi 2014). This leads to potentially unknown uncertainties as well as inconsistencies in comparing AGB estimates derived from different data and using different upscaling methods (Mitchard et al. 2013; Hill et al. 2013).

These issues of heteroscedasticity, i.e. growing variance with tree size, choice of ASE form, small sample size and variability within-species variability across locations and studies, are illustrated clearly in Fig. 2.
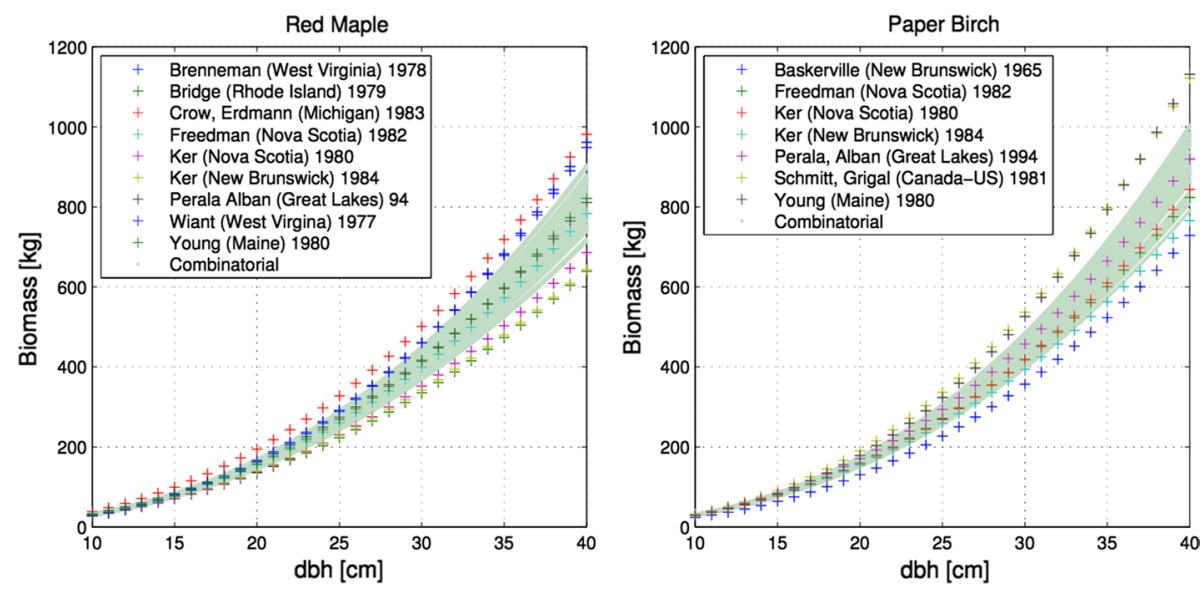

Fig. 2 From Ahmed et al. (2013). An illustration of the variation in estimated AGB values from different ASEs in Ter-Mikaelian and Korzukin (1997) for two deciduous broadleaf species: red maple (Acer rubrum) and paper birch (Betula papyrifera). The estimated biomass is plotted against dbh, the diameter-at-breastheight of the trees. The shaded region represents an estimate of what Ahmed et al. (2013) term $\sigma_{\mathrm{s}}$, the site error in estimated AGB introduced by using ASE model coefficients developed at a different site (estimated via bootstrapping). The growth in uncertainty with $D$ is clearly apparent, even for these relatively small trees 
The most comprehensive attempts to assess the uncertainty of stand-scale AGB derived from ASEs suggest an uncertainty of around 10\%, with potential variation between 5 and 23\% (Chave et al. 2004; Réjou-Méchain et al. 2017) arising from plot-level structural variations. These estimates are based on analysis of the statistical properties of the underlying data and models but are potentially conservative in assumptions of measurement error distributions (normally distributed) and the ability of simple ASE models to capture largescale ecological variations in tree form (Burt 2017; Burt et al. 2018). The uncertainty in AGB at the plot level is less than at the individual tree level, due to the impact of measurement errors reducing with increasing sample size. This plot-scale uncertainty, however, may be less important than the potential issues of bias and heteroscedasticity as outlined above, particularly for larger trees.

These issues mean that in developing accurate EO-derived estimates of AGB with realistic uncertainty, care must be taken to develop appropriate ASEs spanning the full range of biomass likely to be observed, with uncertainty due to ASE form, wood density and upscaling, quantified as far as possible (Ahmed et al. 2013; Hill et al. 2013). Terrestrial laser scanning (TLS) has the capability to address many of these problems, by providing tree- and plot-level AGB estimates which are independent of allometry, unbiased in terms of tree size distributions and with well-quantified uncertainty (Burt 2017; Stovall and Shugart 2018). TLS estimates collected widely and reliably can reduce current uncertainties in terrestrial C stocks, enable improved calibration and validation of AGB products, particularly from EO, and form the basis of improved allometric models. Here, we describe key developments in the use of TLS to estimate AGB, present analysis of uncertainties that should be addressed, and highlight challenges that remain.

\section{TLS for AGB Applications}

Terrestrial laser scanning has developed significantly over the last decade in terms of its ability to deliver highly detailed 3D structural measurements. This has been due in part to the development of robust new sensors and systems at prices that, while still high (approximately few $\$ 10 \mathrm{~s}$ to $\sim 100 \mathrm{~K}$ ), are becoming more affordable for researchers both in real terms, and as their benefits become more apparent. This in turn has led to the development of tools and methods to exploit the resulting point cloud data for ecological applications (Calders et al. 2015; Wilkes et al. 2017; Disney et al. 2018; Disney 2018). This has allowed the use of TLS to move from generalised structural metrics of tree size and shape such as height, DBH, crown size and volume (considered as an enclosing envelope), trunk size and shape, to full reconstruction of 3D tree architecture down to higher order branches, comprising the majority of tree woody biomass. This has been critical to the use of TLS for AGB applications: if full-tree volume can be reliably and near-automatically reconstructed, then estimating AGB is simply a case of multiplying by wood density, $\rho$. Perhaps even more importantly, given that ASEs represent the woody volume of trees, comparison between ASEs and TLS measurements can be made at the volume level, allowing the impact of uncertainty due to $\rho$ to be considered separately from ASE model uncertainty. Reliable automation of $3 \mathrm{D}$ architecture reconstruction is important for comparisons with EO, where the benefits of TLS measurements of large numbers of tree measurements are key.

A range of methods have been proposed to extract full-tree 3D architecture automatically from TLS data (e.g., Yan et al. 2009; Preuksakarn 2012; Raumonen et al. 2013, 2015; 
Hackenberg et al. 2014, 2015, etc.). Disney (2018) outlines some of the various assumptions and trade-offs underpinning them and challenges remaining to improve them. These include: mm-accurate co-registration of multiple point clouds in forest environments, and optimising data collection to achieve this (Wilkes et al. 2017; Paynter et al. 2018); reliable separation of individual trees from large point clouds, particularly in dense, tall forests (Burt et al. 2018); overcoming fundamental limitations of TLS data including occlusion and variable point density; separating wood and leaf points in leaf-on point clouds (Yun et al. 2016; Boni Vicari et al. 2019). Figure 3 shows an example of individual tree segmentation from a 1 ha TLS point cloud from a tropical forest canopy and highlights the challenges of extracting individual trees routinely from larger point clouds. As a general guide, taller and more dense canopies will require more dense TLS sampling to minimise the impacts of occlusion in the upper canopy. Wilkes et al. (2017) show that a 10-m grid sampling pattern allows for reconstruction of branching in dense tropical forest canopies

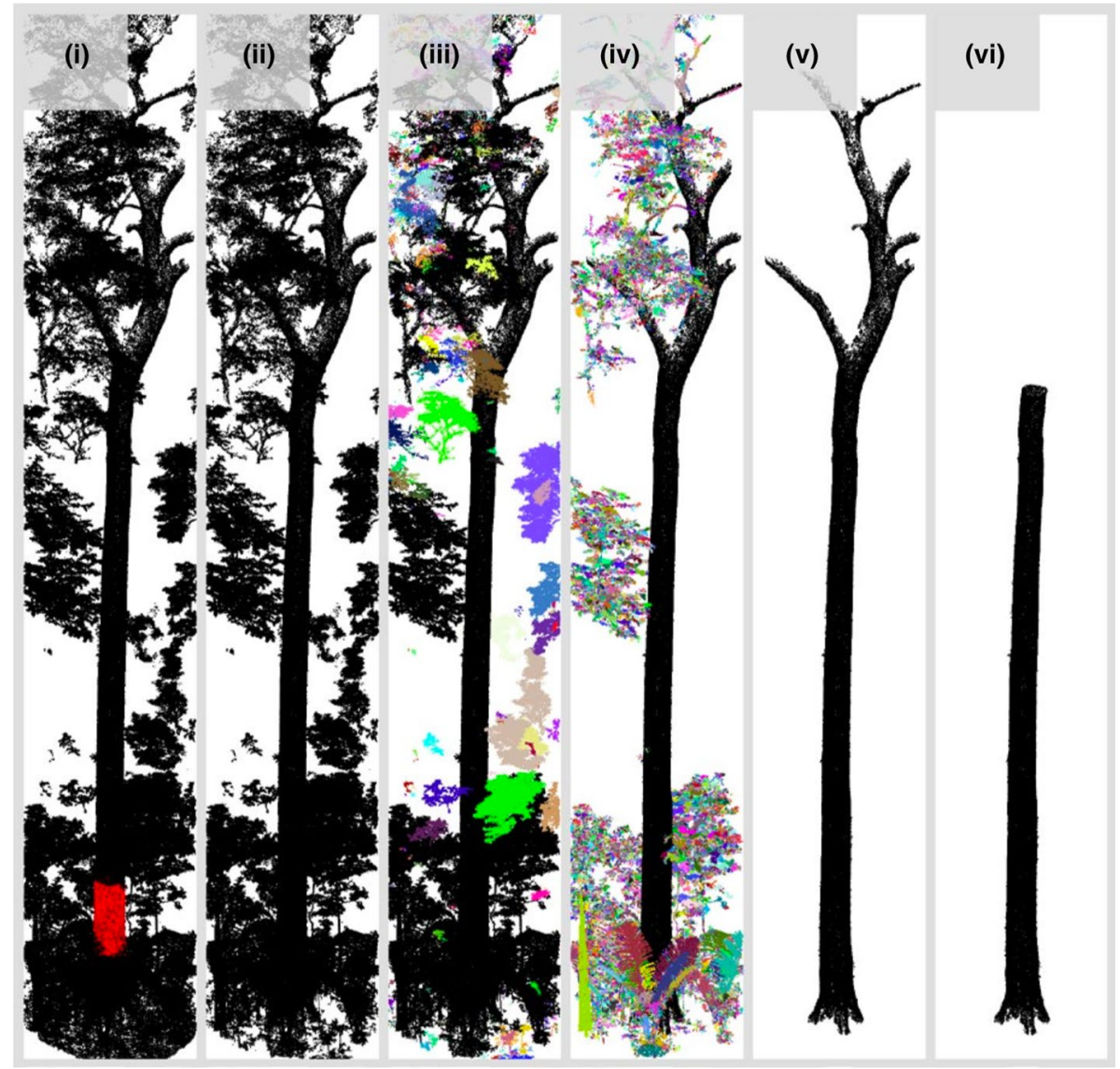

Fig. 3 (reproduced from Burt et al. 2018). Segmenting individual trees from large plot-scale TLS point clouds (collected with a Riegl VZ-400) using Treeseg. Panels show: (i) iterative pass-through filtering to fit enclosing cylinder (red); (ii) plane fitting to remove ground points; (iii), (iv) and (v) iterative clustering and region-based segmentation (multiple colours representing separate segments) to remove neighbouring vegetation; and finally (vi) cylinder fitting to determine the location of first branching and hence the heightto-crown 
taller than $50 \mathrm{~m}$, up to branches of $\sim 5 \mathrm{~cm}$ diameter in the upper canopy. Increasing the scan density provides diminishing returns; the additional cost of data collection and processing more than offset the slight improvement in the very uppermost branches, which in any case contribute the least to AGB.

Various tools are now available to process and analyse TLS data for 3D reconstruction. Most commercial TLS instrument manufacturers provide commercial software tools to allow co-registration, including Leica Cyclone (https://hds.leica-geosystems.com/en/ Leica-Cyclone_6515.htm), RIEGL RiScan Pro (http://www.RIEGL.com/products/softw are-packages/riscan-pro/), etc. Non-commercial software aimed at TLS processing include pylidar (http://www.pylidar.org/en/latest/) and 3D Forest (Trochta et al. 2017 and http:// www.3dforest.eu/). Other non-commercial tools developed for 3D point clouds more generally (particularly ALS and now point clouds derived from structure-from-motion, e.g., from UAVs) are also useful for TLS, for example CloudCompare (https://www.danielgm. $\mathrm{net} / \mathrm{cc} /$ ). This has various features for downsampling, editing and manipulating point clouds as well as for extracting general metrics.

Specific tools developed for addressing 3D reconstruction include:

Treeseg (Burt et al. 2018): codes to segment and isolate individual tree point clouds from much larger point clouds, prior to reconstruction (https://github.com/apburt/trees eg);

TreeQSM (Raumonen et al. 2013): full 3D reconstruction based on fitting cylinder segments to TLS point cloud data. The resulting so-called quantitative structural model (QSM) contains the total and per-branch volume, as well as branch connectivity and insertion angles for each branch (https://github.com/InverseTampere/TreeQSM). Operates on single trees, or potentially at the stand-scale in less dense, more uniform canopies.

SimpleTree (Hackenberg et al. 2015): a full-tree reconstruction approach based on point cloud segmentation (https://github.com/SimpleTree).

$3 D$ Forest (http://www.3dforest.eu/): provides tree size and shape metrics based on manual segmentation and voxellisation, i.e. not explicit 3D and so differing slightly from the largely automated full 3D methods above.

Computree (Othmani et al. 2013): a more forestry-based software platform, designed to be extensible and to derive forestry-related metrics rather than 3D architecture per se (http://computree.onf.fr/?lang=en).

Forestr (Atkins et al. 2018): software tools (in the programming language R) to provide general structural metrics of canopy structural complexity (CSC) metrics, based on the $\mathrm{x}, \mathrm{z}$, or $\mathrm{x}, \mathrm{y}, \mathrm{z}$ position of LiDAR hit density expressed as vegetation area index (VAI) (https://github.com/atkinsjeff/forestr).

A key problem is how to assess the accuracy and uncertainty of the resulting 3D tree volumes. The only way to do this really is via destructive harvesting. The practical obstacles to this mean it is very difficult and so has been done in only a few cases. Figure 4, from Disney (2018) and reproduced here, compares examples from Calders et al. (2015 for three Eucalyptus species, Australia, Gonzalez de Tanago et al. (2018) in Guyana, Indonesia and Peru; and Momo Takoudjou et al. (2017) in eastern Cameroon. These efforts in validating TLS-derived AGB show that the method agrees with destructive harvest values with $r^{2}>0.95$ in all cases. This is robust across varying canopy types, including large tropical trees and trees with buttressed trunks. Absolute agreement between TLS-derived and harvested AGB agrees to within $10 \%$ at the individual tree level for all trees in these studies 
(a)

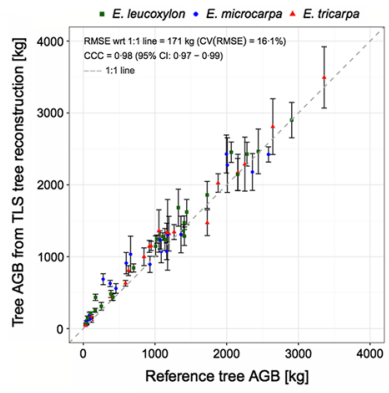

(b)

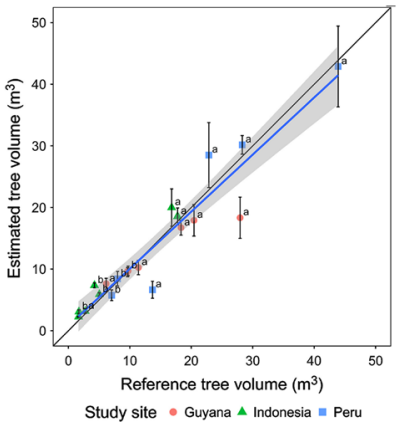

(c)

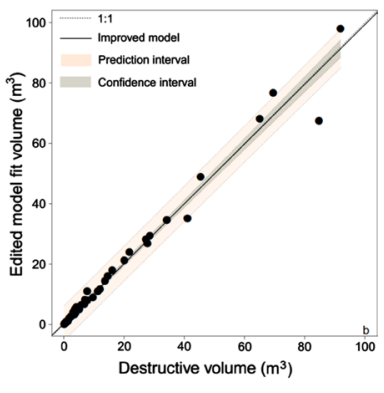

Fig. 4 From Disney (2018). Comparison of TLS-derived estimates of tree AGB and volume, with values from destructive harvests: a Calders et al. (2014) TLS-derived and weighed AGB for three Eucalyptus species, Australia; b Gonzalez de Tanago et al. (2018) TLS-derived and destructive volume across three tropical sites, with buttressed and non-buttressed trees marked a, b, respectively; c Momo Takoudjou et al. (2017) TLS-derived and destructive volume from eastern Cameroon. In the latter two cases, the shaded area is the $95 \%$ confidence interval of the regression fit

and to within $2 \%$ in the majority of cases. Buttressed trees are important for tropical forests as they can make up significant numbers of large trees in tropical plots. Disney et al. (2018) show that the buttressed trunks can introduce greater uncertainty in TLS-derived AGB at the single tree level (up to $10 \%$ over/under-estimation), due to the issue of fitting cylinders to non-cylindrical trunk forms. However, these fitting errors are randomly distributed and so tend to cancel out at the plot level. Buttressed trunks are known to be an issue for DBH-based allometry more generally, and TLS can help address this (Noelke et al. 2015). Less automated but more flexible volume fitting approaches such as mesh grids (ibid.) and outer hull models (OHMs; Stovall et al. 2017) can also be used to potentially address this issue. This is another area where TLS may help in cal/val of AGB derived from EO or survey methods, based on ASEs where buttressed trunk form is not well represented. Additionally, AGB derived from plot survey measurements of DBH have to contend with the issue of where and how DBH is measured for buttressed trees (http://www.rainfor.org/ upload/ManualsEnglish/RAINFOR_field_manual_version_2016.pdf) and then how this is accounted for in the tapered cylinder assumption of ASE form.

These direct validation efforts illustrated in Fig. 4 demonstrate very clearly that TLSderived AGB is both accurate and robust, across all tree size classes. This is the strongest and most direct evidence that TLS can be used to test the existing ASEs, as well as to augment allometric datasets, to include more, larger trees. This potentially addresses one of the fundamental limitations of ASEs highlighted above.

More generally, Disney et al. (2012) proposed using simulated TLS point clouds of 3D model trees where instrument, acquisition and tree architecture properties are known a priori. This allows for sensitivity and uncertainty analysis and has been used to test some of the approaches above (Raumonen et al. 2013; Hackenberg et al. 2014; Burt et al. 2018). The utility of this 3D simulation approach can also be tested by comparing simulations from the retrieved 3D architectural models with other, indirect estimates of canopy properties, including reflectance, leaf area index (LAI), etc. The advantage of this is that many of these EO-derived estimates of canopy properties have uncertainty which is much better-characterised than for estimates of AGB. Figure 5 illustrates this approach, showing a comparison of simulated and actual top-of-canopy 

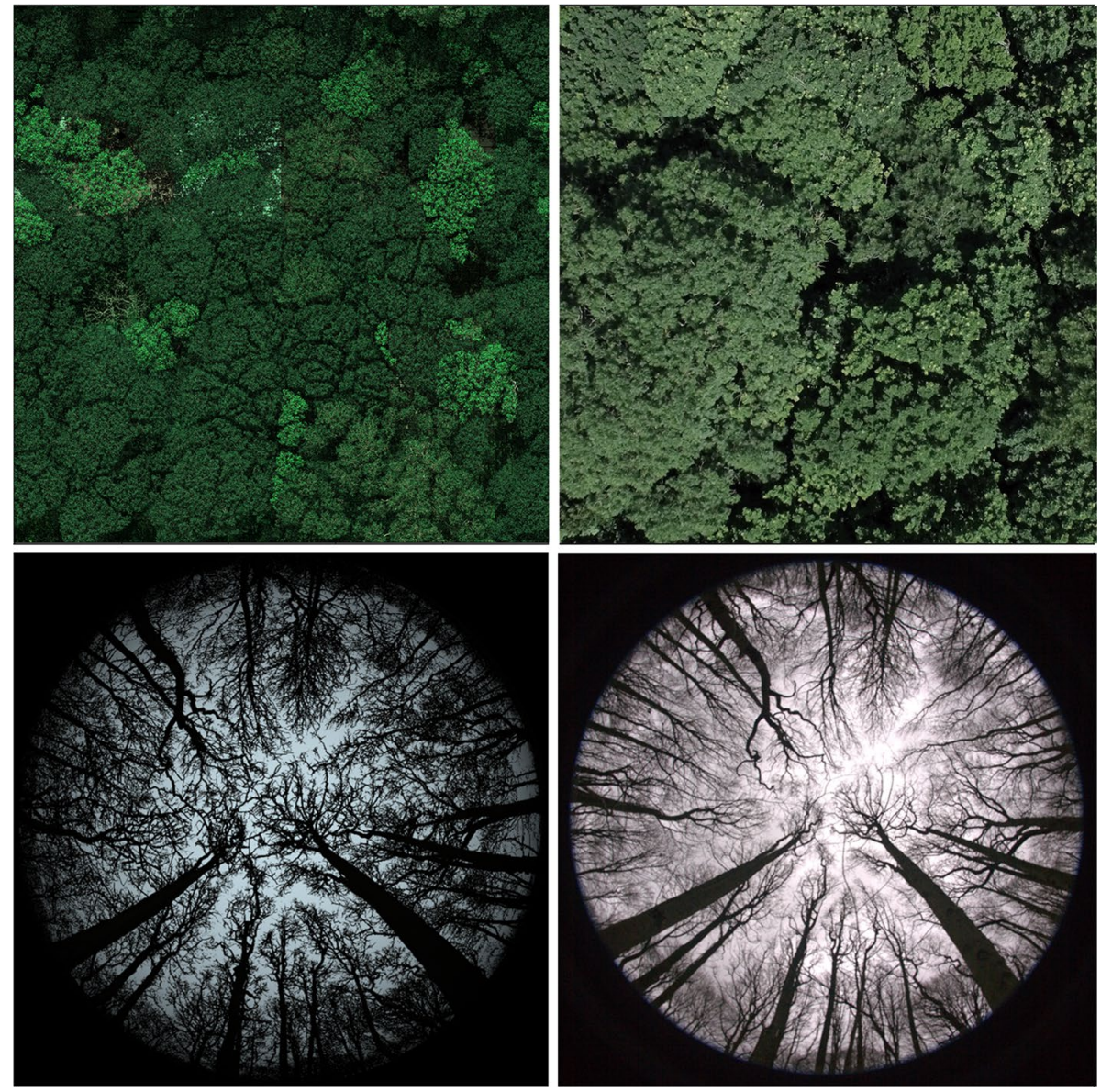

Fig. 5 Adapted from Calders et al. (2018). Upper row: simulated image of a deciduous woodland (left) and UAV RGB image over the canopy on which this model simulation is based (right). This is intended to be an indicative simulation rather than an exact representation, due to lack of leaf spectral and size information in the upper canopy. Lower row: simulated (left) and measured (right) hemiphotos in leaf-off conditions from the same location within the canopy. In this case, the model canopy structure is intended as a direct copy of the observed

red/green/blue (RGB) values obtained using an unmanned autonomous vehicle (UAV) and hemiphoto, where the simulations are derived from a $3 \mathrm{D}$ canopy architectural model derived from 1 ha TLS point cloud collected in Wytham Woods, UK (Calders et al. 2018).

An additional, very useful software tool in the context of AGB uncertainty, which can and should be applied once new ASEs are developed, from TLS or elsewhere, is the $\mathrm{R}$ package developed by Réjou-Méchain et al. (2017) to allow the uncertainty in new ASEs to be quantified (https://cran.r-project.org/web/packages/BIOMASS/index.html). 


\section{TLS to Underpin Satellite-Derived AGB: Developments and Challenges}

As outlined above, TLS can provide several new advantages to AGB estimation which are likely to make it a significant development for satellite-derived estimates. All EO-derived estimates of AGB depend on indirect retrievals, typically via height allometry for lidar and RADAR estimates, but also via empirical backscatter-biomass relationships. The benefits of TLS can make vital contributions to calibration and validation (cal/val) efforts, including: improving the existing ASEs via the inclusion of many more trees across a much wider distribution of size and shape across different biomes; testing assumptions underlying, and form of, ASEs to better characterise uncertainty; to provide independent estimates of AGB to validate retrievals, particularly in tropical and other high biomass regions where groundbased estimates are rare or non-existent; to allow development of new highly detailed 3D radiative transfer (RT) models for simulating EO signals. This allows for new algorithm development and testing and benchmarking of simpler RT models, where canopy structural properties are known a priori (Widlowski et al. 2013; Calders et al. 2018; and Fig. 5 above).

The benefit of TLS for EO-derived AGB is exemplified by its inclusion by CEOS as a key method in its recommended protocol for cal/val of AGB. Stovall and Shugart (2018) present a framework for how TLS can be used to improve EO estimates of AGB, and this is reproduced in Fig. 6. They point out that TLS can figure prominently in both the measurement of plot-scale biomass and structure for improving EO retrievals, new allometric models, for pre-launch calibration and post-launch validation of EO estimates via plot measurements of biomass.

Some additional benefits of TLS for EO cal/val are shown in Fig. 7. This illustrates how volume estimates derived from TLS measurements can be used to understand the EO signal, as well as quantifying forest structural differences across biomes. Figure 7 illustrates differences between sites in how wood volume (and hence biomass) is distributed across branch size classes, with volume skewed towards smaller branches higher in the canopy in French Guiana; or across a wider range of branch sizes in Ghana. The two

(a)

(b)

(c)

(d)

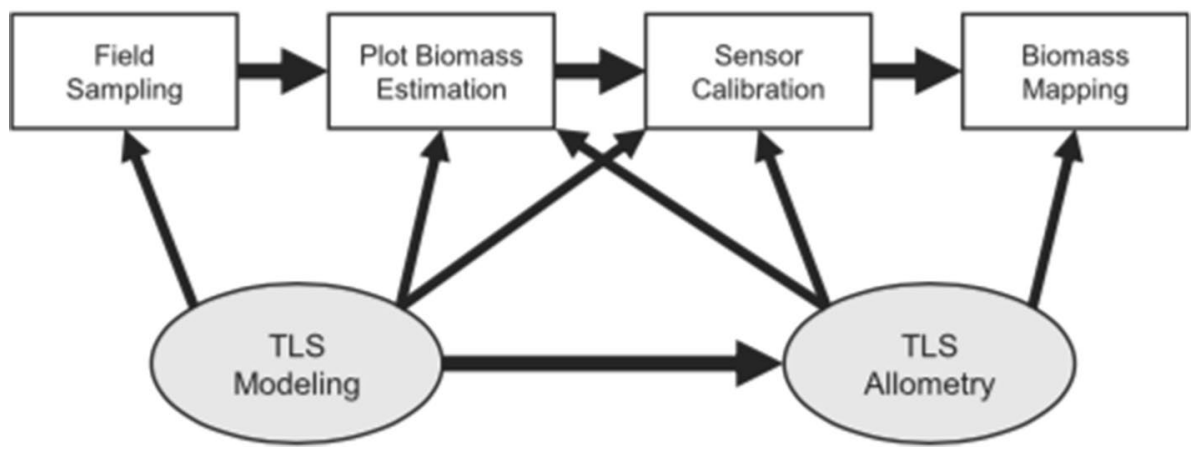

Fig. 6 From Stovall and Shugart (2018). A flow diagram outlining how TLS can be used to address the limitations of ASEs for EO-derived estimates of AGB, specifically via calibration and validation. They note that in a TLS can provide unbiased (by size class) estimates of standard forestry properties (DBH, height, etc.); b non-destructive estimates of AGB to test and develop improved ASEs; $\mathbf{c}$ and $\mathbf{d}$ plot-level volume/ biomass estimates for calibration and validation of EO products 

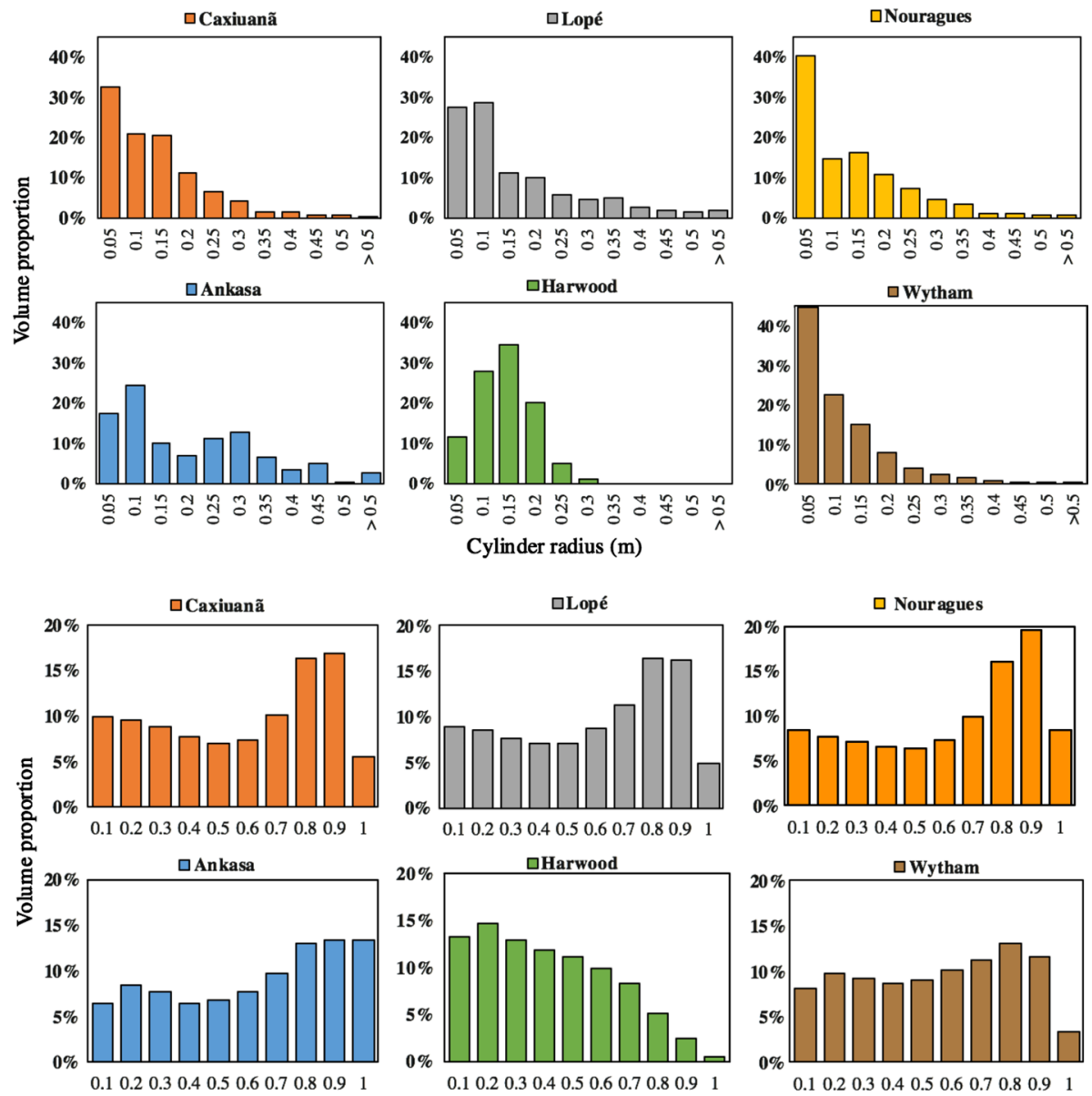

Fig. 7 From Tang (2017). Comparison of the TLS-derived volume as a function of tree size across four tropical sites (Caxiuanã, Brazil; Lopé, Gabon; Nouragues, French Guiana and Ankasa, Ghana), plantation conifer (Harwood, UK) and deciduous woodland (Wytham Woods, UK). Volume is derived from Quantitative Structural Model (QSMs) fitted to TLS data, separated into $11 \times 5 \mathrm{~cm}$ size diameter classes from $<5 \mathrm{~cm}$ to $\geq 50 \mathrm{~cm}$, with the proportion of volume in each size class shown (top panel). The lower panel shows the same information as a function of relative tree height

UK sites stand out as we would expect (and hope!), particularly the plantation conifer canopy (Sitka spruce). When expressed as a function of canopy height (lower panel), the differences between the tropical and UK forests are less pronounced, except for the conifer which shows a characteristic dominant trunk and small crown biomass. Information of this sort is critical for understanding the dependence of ASE-derived estimates of AGB based on height. This is particularly true for RADAR retrievals of biomass at longer wavelengths, e.g., for ESA BIOMASS at P-band $(70 \mathrm{~cm})$. These retrievals assume the dominant portion of the P-band backscatter signal over tropical forests arises from a peak of biomass in the upper part of the canopy (Le Toan et al. 2011; Garestier and Le Toan 2010). Smaller branches and leaves in the upper part of the canopy become 
more important for backscatter-AGB relationships from shorter wavelength RADAR, L-band for example (Mermoz et al. 2015). Measuring these components accurately from TLS is likely to be a greater challenge, as outlined below.

Figure 8, reproduced from Stovall and Shugart (2018), is an explicit example of how TLS can provide improved ASEs for biomass estimation from EO. They show that for species-specific ASEs, uncertainty in allometric estimates of AGB can be nearly halved through the use of TLS-derived ASEs compared to destructive harvest alone. Perhaps even more importantly, the TLS estimates have low or no bias (Calders et al. 2015; Gonzalez de

(a)

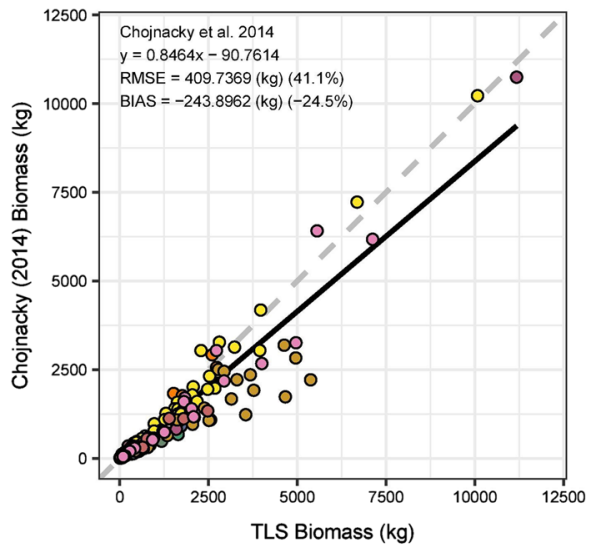

(c)

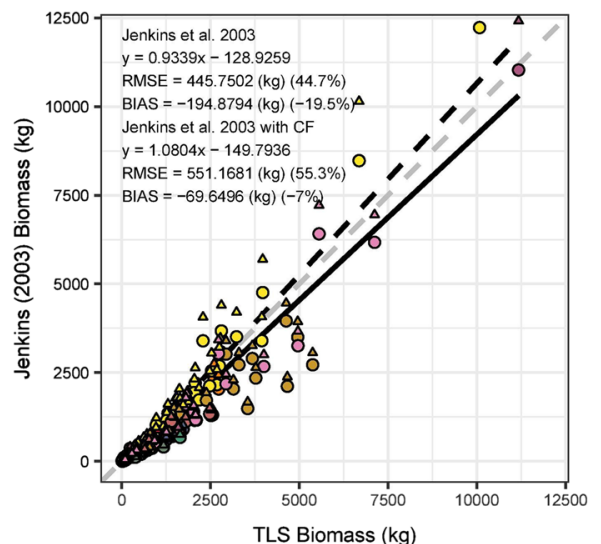

(b)

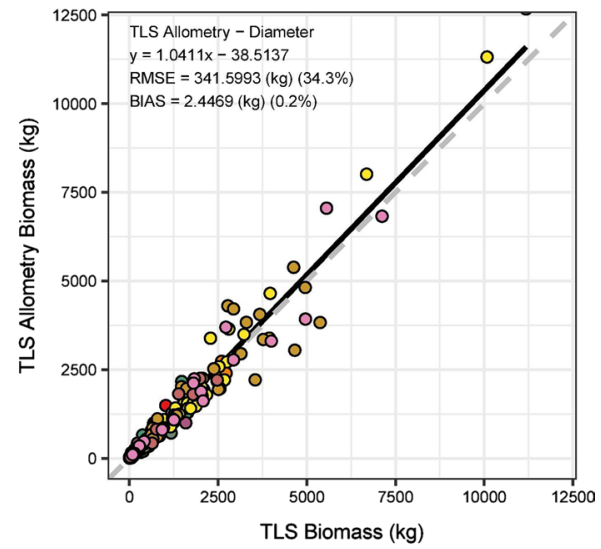

(d)

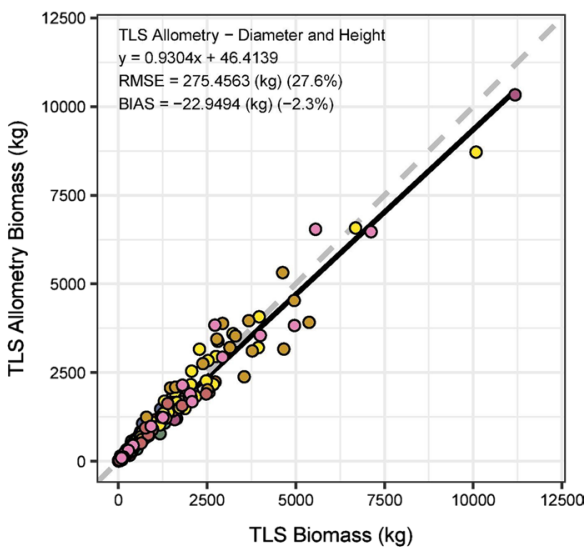
Species

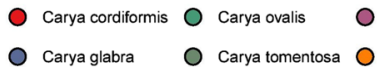

Fagus grandifolia

O Liriodendron tulipifera

Quercus prinus

Fraxinus americana $\bigcirc$ Quercus alba

Quercus rubra

Fig. 8 From Stovall et al. (2018). Comparison of species-specific AGB derived from full volume QSM reconstruction of TLS measurements (x axis in each case), with previously published species-specific DBH and H-DBH ASEs (left column). The right hand panels compare AGB estimated from ASEs derived from TLS measurements of DBH (top right) and DBH and $\mathrm{H}$ (bottom right), with the full TLS-derived biomass 
Tanago et al. 2018; Momo Takoudjou et al. 2017), compared to 7 to $20 \%$ for the ASEs from destructive harvesting.

Stovall et al. (2018) conclude that TLS can produce unbiased AGB estimates, importantly by including larger diameter trees. They suggest that ASEs should be developed with sample sizes of at least 100 individuals to ensure equations have high precision and low bias. The issue of bias is discussed by Burt et al. (2018) who note that measurements of unbiased size distributions, and larger trees in particular, are vital to reduce uncertainty in AGB estimated via allometry. They note that the issue of heteroscedasticity means that uncertainty in ASE-derived AGB will always tend to be greater in higher biomass areas, but quantifying this uncertainty drastically improves the usefulness of resulting EO estimates.

One other area where TLS has the potential to improve EO-derived AGB is in the impact of uncertainty in wood density, $\rho$. Stovall et al. (2018) note that biomass estimates will vary as a function of intra-specific and site-level variation in wood density from published average values, as well as throughout individual trees. They conclude that quantifying wood density variability is essential for quantifying uncertainty in TLS-based biomass estimates. However, accurate estimates of wood density are critical to estimating AGB either from both allometry and TLS. As noted above, by comparing at the volume level wherever possible, as facilitated by TLS, the issue of wood density can be separated from the problem of uncertainty in the ASE or TLS-derived volume. Improved estimates of site and species level $\rho$ can then be added where possible, to improve biomass estimates. 3D models from TLS are also opening the possibility for exploring the relationship between wood density and tree mechanical properties (Jackson et al. 2019).

The challenges to wider adoption of TLS for AGB estimation are broadly technical, cost and scaling and are all linked. The technical challenges lie in how to collect TLS data at plot scales and then retrieve structural properties, notably full 3D tree volume, with sufficient accuracy and quantified uncertainty. Resolving smaller branches in tall, dense leaf-on canopies is a challenge for TLS, which will tend to increase uncertainty in these components of AGB at the tree-scale. Comparisons between TLS-derived and harvested AGB at the individual tree level seem to show little or no bias, in part because the most poorly resolved branches are the smallest. This is potentially improved with higher density point clouds and with more effective methods to separate wood and leaf points (Boni Vicari et al. 2019). However, published comparisons tend not to look at these smaller components explicitly; more work is needed to quantify the impact of these possible sources of bias.

An additional challenge is how to do this for different groups using TLS instruments with different properties and across various environments. As outlined above, the development of standardised measurement protocols and software tools that aimed at processing TLS data for ecological applications specifically is helping to reduce these technical barriers. However, until acquisition and processing becomes 'routine', TLS for 3D volume estimates will still be the preserve of a relatively small number of groups and users. The cost of TLS is another potential barrier, with instruments costing upwards of $\$ 100 \mathrm{~K}$ being out of reach for many/most researchers. However, if the value of the measurements provides demonstrably unique, important information for addressing key uncertainties in large-scale estimates of AGB, then funding is likely to become available. Wider adoption of TLS also provides impetus for development of new tools and instruments. Compact, lightweight and lower-cost TLS (e.g. $\$ 20 \mathrm{~K}$ ) has been developed which provides shorter-range, lowerprecision measurements, but may provide some of the benefits of the higher-cost instruments for AGB estimates, e.g., by rapidly capturing tree volume for the larger parts of trees (Bauwens et al. 2016; Paynter et al. 2016). Figure 9 shows an example of Hemlock trees 

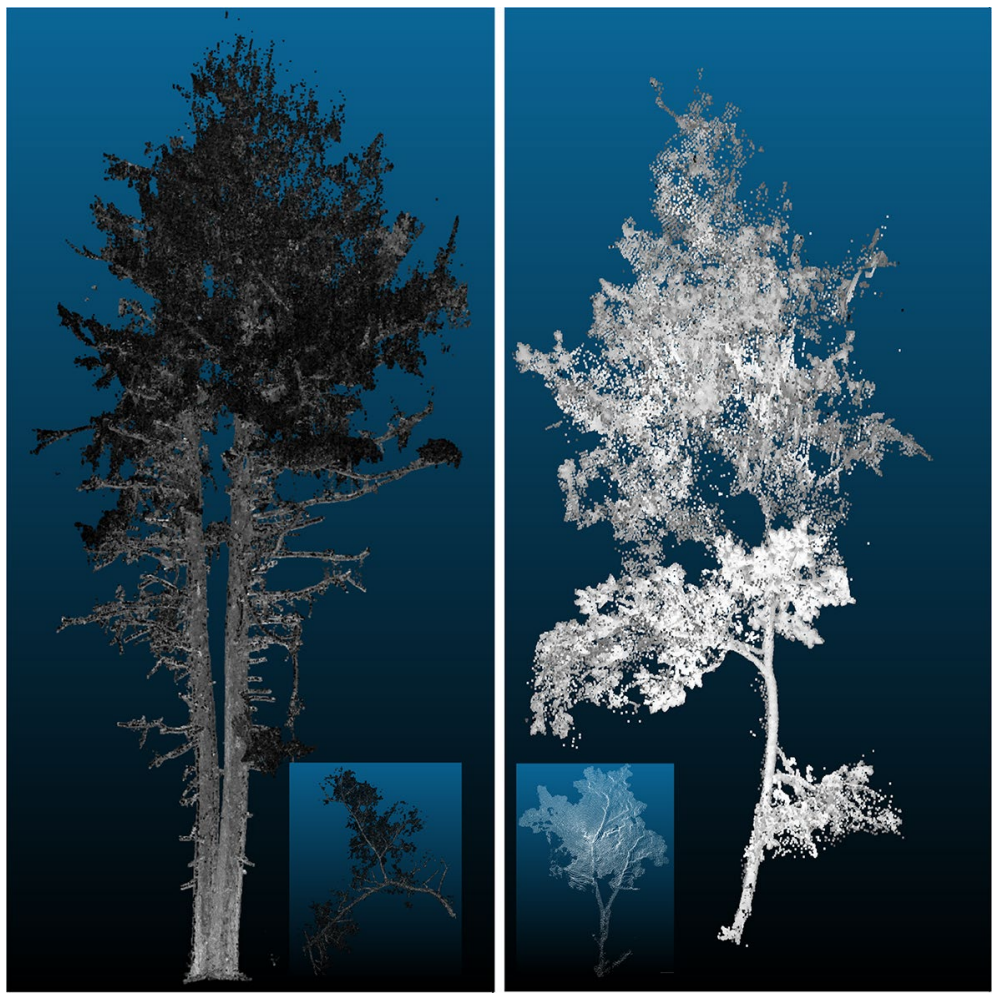

Fig. 9 Left: TLS data from a Leica BLK360 of an Eastern Hemlock (Tsuga canadensis) measured in the Smithsonian Institute ForestGeo plot at Harvard Forest, MA, USA. The tree is suffering from defoliation due to infestation by the Hemlock Woolly Adelgid (HWA). From the TLS, the tree has DBH 81.5, H 24.1 m and volume of $10.5 \mathrm{~m}^{3}$. Right: TLS data from the wide beam Canopy Biomass Lidar (CBL) of an Eastern Hemlock Tree unaffected by HWA, with TLS-derived DBH-12.3 cm, $H=9.65 \mathrm{~m}$ and volume $0.35 \mathrm{~m}^{3}$. Insets in each case show close-up views of a branch from each tree, at the same scale

scanned in Harvard Forest, using lightweight TLS systems that are \$10-20 K and have been developed for more general 3D measurements, both ecological or also for mobile mapping. The inset views in this case show where the TLS is unable to resolve separate branches and needles.

The rapid development of new low-cost TLS instruments has the potential to provide $\mathrm{cal} / \mathrm{val}$ information with specific benefits. While it is desirable to make the most accurate ground measurements possible of tree volume and AGB for EO cal/val, CEOS LPV recognises the need for a hierarchical approach, to allow for collecting the best ground data within the constraints of resources (cost, time, personnel, access, etc.) and to allow for improvement over time (CEOS LPV 2019). Useful measurements can be taken using lower-cost, lower-precision TLS systems, potentially by more groups, over larger areas and/or more often, despite the resulting lower accuracy and detail. The accuracy requirement for $\mathrm{cal} / \mathrm{val}$ for EO will depend on the nature of the EO estimates themselves and the region of interest. Duncanson et al. (2019 this volume) list the requirements for AGB accuracy for a range of space missions, all of which (where specified) set $\leq 20 \%$ as the accuracy requirement. This suggests that ground measurements capable of doing better than this will 
provide useful cal/val data. Lower-cost TLS instruments will not produce accurate volume estimates of trees $>30 \mathrm{~m}$ in dense forests but are certainly capable of providing height and DBH for shorter, less dense canopies. The rapid development and improvement of these lower-cost instruments and associated processing software mean that their utility is only likely to increase. Such instruments will increasingly have a place in wider adoption of TLS methods for AGB estimation, particularly where cost is the primary barrier.

Lastly, the challenge of scale is how to integrate TLS, which excels at the individual tree to plot scale $(\sim \mathrm{ha})$, with other measurements including manual survey measurements, manned and unmanned aerial lidar systems (ALS, UAS), and satellite observations. TLS has the potential to provide additional opportunities to exploit these measurements for AGB estimates, but the choice of scales at which to collect TLS and the type of plots to use are open questions. The application of TLS for AGB estimation and comparison to manual census, air- and spaceborne estimates is still new, and very much in development. Thus far, TLS survey plots have typically been selected to match the size and shape of the base unit of the other core measurements for a given application. For forest inventory applications, this is typically plots of 0.04-0.25 ha, circular or rectangular (Edwards 1998; USFS 2019); for tropical forest studies, plots are typically 1 ha square (Phillips et al. 2002). Wilkes et al. (2017) discuss the impact of varying density and arrangement of TLS scan locations for AGB estimation specifically. In particular, they show that the trade-off between more, smaller plots or fewer larger plots is not straightforward. The former may be tempting to enable sampling a wider range of forest type, climate, soil and other conditions, but the quality of the resulting TLS point cloud will be much lower than for larger plots. The larger the plot, the more TLS locations there will be that can contribute to the point cloud of a specific tree. This is particularly true for tall, dense canopies typical of tropical forests. For a 1 ha plot and with a 10-m scanning grid, there are 121 locations from which a tree might be 'seen', from $100 \mathrm{~m}$ away (or more from corner to corner). A 0.25 ha plot will only have 36 scan locations and the resulting extracted tree volume models will be of much lower quality, particularly in the upper canopy. Moreover, locations further from a tree often contribute more to the upper part of the tree than locations close by, due to the oblique angle through the canopy.

A related issue is how TLS measurements required for specific forest inventory applications may be used in the context of EO-derived AGB cal/val. Liang et al. (2018) present a comparison of forestry parameter extraction methods using a common TLS dataset that highlights some important issues of the impact of forest structure on the resulting point cloud. The comparison is carried out on smaller plots $(0.1 \mathrm{ha})$ than those more suited for EO-derived AGB comparisons and using phase-shift TLS which has limitations of range and partial hits for tall forests (Newnham et al. 2012). These issues notwithstanding, an important conclusion is that the higher the density of smaller stems $(\mathrm{DBH}<20 \mathrm{~cm})$ in a plot, the greater the impacts of occlusion will be. TLS data collection for AGB estimation in this type of canopy, particularly young, dense or plantation forests, or forests dominated by lianas (Krishna Moorthy et al. 2018), will need to consider these possible limitations: increasing the scan density, plot size and by using time-of-flight longer range TLS will all help, but at increased cost.

An additional challenge comes for integration of TLS data with ALS or unmanned Aerial Lidar Systems (UAS). To match clouds at the crown-scale and finer requires accurate (cm-scale) co-location of the different lidar datasets, requiring very accurate RTK GPS or equivalent. Even then, the various point clouds may need manual co-registration, particularly for ALS point clouds where the absolute geolocation accuracy may be lower. The denser the airborne point cloud, the easier it will be to identify possible ground control 
points and leading to better manual matching, i.e. typically likely to be easier for UAS than ALS. Methods for merging these data are likely to develop and improve as they become more widely used. Specific issues of ALS and UAV lidar acquisition and characteristics for AGB estimation are discussed elsewhere.

The requirement for ASEs will remain, to enable wide-scale assessment of AGB, particularly from EO but also to provide continuity with the large body of the existing plotscale census measurements. Consequently, we foresee the main role of TLS in EO-derived estimates of AGB will be initially to enable improved ASEs from a much larger sample of trees across a wider size distribution than is currently possible (calibration). TLS will also provide estimates of AGB at the same scale as those derived from EO, particularly from spaceborne measurements, allowing for improved validation of these products. In the longer term, TLS can potentially provide a better understanding of the impacts of structural variations (trunk form, crown size and shape) and within-tree wood density on the ASE approach. Lastly, 3D data derived from TLS enable development of more realistic $3 \mathrm{D}$ radiative transfer models to help quantify uncertainty in spaceborne observations (Calders et al. 2018). Structurally consistent models across optical and microwave domains will improve our ability to combine spaceborne data for AGB across these domains.

\section{Conclusions}

Terrestrial laser scanning offers considerable benefits to improving estimates of aboveground biomass from satellite observations. These benefits lie in a number of areas: improvement of the existing allometric scaling equations used to relate tree $\mathrm{H}$ and $\mathrm{DBH}$ to AGB, via the inclusion of many more samples of tree volume/biomass; the reduction of bias in ASEs by incorporating more large trees into ASEs to help address the fundamental issue of heteroscedasticity of AGB allometry; help develop new EO retrievals, through testing the assumptions of the existing retrieval models and by the use of full 3D radiative transfer models with which to simulate EO signals with known structural and radiometric uncertainties; by quantifying uncertainty in retrieved AGB estimates through pre-launch modelling and calibration, and post-launch validation at the plot scale; and lastly by providing a link between measurements made at the tree and plot scale, particularly manual forestry measurements and observations of varying spatial scales from airborne, unmanned aerial systems (UAS) and beyond. The interest in TLS has prompted many advances including new lower-cost TLS systems, methods to process TLS data more rapidly and consistently and protocols specifically aimed at collection of TLS data specifically for AGB applications. Further assessment of the uncertainty in the TLS model reconstructions is required, particularly in tall, dense canopies. Comparisons of TLS-derived and harvested AGB may agree very closely at the tree level, but this may overlook divergence within different size components. Further standardisation of data acquisition, automation of processing and more detailed testing of the resulting 3D reconstructions will bring TLS further into the mainstream for biomass estimation from space.

Acknowledgements MD acknowledges funding support from: NERC NCEO; NERC Standard Grants NE/N00373X/1 and NE/P011780/1; European Union's Horizon 2020 research and innovation programme under Grant Agreement No. 640176 for the EU H2020 BACI Project. MD gratefully acknowledges the support of the ISSI, Bern, for arranging and funding the Workshop Forest Biomass and Structure from Space, 6-9 November 2017, which provided the impetus for this article. CS was supported by NASA Grant 
NNX16AP78A; all authors have benefited from the support of NSF RCN 1455636. We gratefully acknowledge the help of Peter Boucher at U Mass Boston for providing lidar examples for Fig. 9.

Open Access This article is distributed under the terms of the Creative Commons Attribution 4.0 International License (http://creativecommons.org/licenses/by/4.0/), which permits unrestricted use, distribution, and reproduction in any medium, provided you give appropriate credit to the original author(s) and the source, provide a link to the Creative Commons license, and indicate if changes were made.

\section{References}

Ahmed R, Siqueira P, Hensley S, Bergen K (2013) Uncertainty of forest biomass estimates in north temperate forests due to allometry: implications for remote sensing. Remote Sens 5:3007-3036. https:// doi.org/10.3390/rs5063007

Atkins JW, Bohrer G, Fahey RT, Hardiman BS, Morin TH, Stovall AE, Zimmerman N, Gough CM (2018) Quantifying vegetation and canopy structural complexity from terrestrial Li DAR data using the forestr r package. Methods Ecol Evol 9(10):2057-2066

Avitabile V et al (2016) An integrated pan-tropical biomass map using multiple reference datasets. Glob Change Biol 22(4):1406-1420. https://doi.org/10.1111/gcb.13139

Baccini A et al (2012) Estimated carbon dioxide emissions from tropical deforestation improved by carbon-density maps. Nat Clim Change 2:182-185

Baskerville GL (1972) Use of logarithmic regression in the estimation of plant biomass. Can J For Res 2:49-53. https://doi.org/10.1139/X72-009

Bauwens S, Bartholomeus H, Calders K, Lejeune P (2016) Forest inventory with terrestrial LiDAR: a comparison of static and hand-held mobile laser scanning. Forests 7(6):127

Boni Vicari M, Disney MI, Wilkes P, Burt A, Calders K, Woodgate W (2019) New framework for separating leaf and wood in terrestrial LiDAR point clouds. Methods Ecol Evol. https://doi. org/10.1111/2041-210X.13144

Brown S, Lugo E (1984) Biomass of tropical forests: a new estimate based on forest volumes. Science 223:1290

Burt A (2017) New 3D measurements of forest structure. Ph.D. thesis, University College London, London

Burt A, Disney MI, Calders K (2018) Extracting individual trees from lidar point clouds using treeseg. Methods Ecol Evol. https://doi.org/10.1111/2041-210X.13121

Calders K, Newnham G, Burt A, Murphy S, Raumonen P, Herold M, Culvenor D, Avitabile V, Disney MI, Armston J, Kaasalainen M (2014) Non-destructive estimates of above-ground biomass using terrestrial laser scanning. Methods Ecol Evol. https://doi.org/10.1111/2041-210X.12301

Calders K, Newnham G, Armston J, Disney MI, Schaaf C, Paynter I (2015) Terrestrial LIDAR for forest monitoring, Chapter 2.10 in GOFC-GOLD (2015) A sourcebook of methods and procedures for monitoring and reporting anthropogenic greenhouse gas emissions and removals associated with deforestation, gains and losses of carbon stocks in forests remaining forests, and forestation. GOFCGOLD Report version COP21-1, (GOFC-GOLD Land Cover Project Office, Wageningen University, The Netherlands)

Calders K, Origo N, Burt A, Disney MI, Nightingale J, Raumonen P, Åkerblom M, Malhi Y, Lewis P (2018) Realistic forest stand reconstruction from terrestrial LiDAR for radiative transfer modelling. Remote Sensing 10(6):933. https://doi.org/10.3390/rs10060933

CEOS LPV (2019) https://lpvs.gsfc.nasa.gov. Accessed Feb 2019

CEOS LPV WGCV Biomass (2019): https://lpvs.gsfc.nasa.gov/Biomass/AGB_home.html. Accessed Feb 2019

Chave J, Condit R, Aguilar S, Hernandez A, Lao S, Perez R (2004) Error propagation and scaling for tropical forest biomass estimates. Phil Trans R Soc Lond B Biol Sci 359(1443):409-420

Chave J, Andalo C, Brown S, Cairns MA, Chambers JQ, Eamus D, Fölster H, Fromard F, Higuchi N, Kira T, Lescure JP (2005) Tree allometry and improved estimation of carbon stocks and balance in tropical forests. Oecologia 145(1):87-99

Chave J, Muller-Landau HC, Baker TR, Easdale TA, Steege HT, Webb CO (2006) Regional and phylogenetic variation of wood density across 2456 neotropical tree species. Ecol Appl 16(6):2356-2367

Chave J, Coomes D, Jansen S, Lewis SL, Swenson NG, Zanne AE (2009) Towards a worldwide wood economics spectrum. Ecol Lett 12(4):351-366 
Chave J et al (2014) Improved allometric models to estimate the aboveground biomass of tropical trees. Glob Change Biol 20:3177-3190. https://doi.org/10.1111/gcb.12629

Clark DB, Kellner JR (2012) Tropical forest biomass estimation and the fallacy of misplaced concreteness. J Veg Sci 23:1191-1196

Crowther TW, Glick HB, Covey KR, Bettigole C, Maynard DS et al (2015) Mapping tree density at a global scale. Nature 525:201-205. https://doi.org/10.1038/nature14967

Danson FM, Gaulton R, Armitage RP, Disney MI, Gunawan O, Lewis P, Pearson G, Ramirez AF (2014) Developing a dual-wavelength full-waveform terrestrial laser scanner to characterize forest canopy structure. Agric For Meteorol 198:7-14

Disney MI (2018) Terrestrial lidar: a 3D revolution in how we look at trees. New Phytol. https://doi. org/10.1111/nph.15517

Disney MI, Lewis P, Raumonen P (2012) Testing a new vegetation structure retrieval algorithm from terrestrial lidar scanner data using 3D models, Silvilaser 2012, 16-19 September, Vancouver, BC, Canada

Disney MI, Boni Vicari M, Calders K, Burt A, Lewis S, Raumonen P, Wilkes P (2018) Weighing trees with lasers: advances, challenges and opportunities. Interface Focus 8(2):20170048. https://doi. org/10.1098/rsfs.2017.0048

Douglas ES, Martel J, Li Z, Howe G, Hewawasam K, Marshall RA, Schaaf CL, Cook TA, Newnham GJ, Strahler A, Chakrabarti S (2015) Finding leaves in the forest: the dual-wavelength Echidna lidar. IEEE Geosci Remote Sens Lett 12(4):776-780

Duncanson L, et al (2019) The importance of consistent global forest aboveground biomass product validation, chapter X in SSS ISSI book no. 71, eds. Scipal, Dubayah, Le Toan, Quegan, Cazenave and Lopez

Duncanson L, Rourke O, Dubayah R (2015) Small sample sizes yield biased allometric equations in temperate forests. Nature Sci. Rep. 5:17153. https://doi.org/10.1038/srep17153

Edwards PN (1998) Timber measurement: a field guide. Forestry Commission Booklet 49, ISBN 0 855384034

Feldpausch TR, Banin L, Phillips OL, Baker TR, Lewis SL, Quesada CA, Affum-Baffoe K, Arets EJ, Berry NJ, Bird M, Brondizio ES (2010) Height-diameter allometry of tropical forest trees. Biogeosci Discuss 7:7727-7793

Garestier F, Le Toan T (2010) Estimation of the backscatter vertical profile of a pine forest using single baseline P-band (Pol-)InSAR data. IEEE Trans Geosci Remote Sens 48(9):3340-3348. https://doi. org/10.1109/TGRS.2010.2046669

GCOS (2010). Implementation plan for the global observing system for climate in support of the UNFCCC (2010 update). GCOS-138 (GOOS-184, GTOS-76, WMO-TD/No. 1523). World Meteorological Organization. url: http://wmo.int/pages/prog/gcos/Publications/gcos-138.pdf. visited on 21 July 2017

Gonzalez de Tanago J, Lau A, Bartholomeus H, Herold M, Avitabile V, Raumonen P, Martius C, Goodman RC, Manuri S, Burt A, Disney MI, Calders K (2018) Estimation of above-ground biomass of large tropical trees with terrestrial LiDAR. Methods Ecol Evol 9(2):223-234. https://doi. org/10.1111/2041-210X.12904

Hackenberg J, Morhart C, Sheppard J, Spiecker H, Disney MI (2014) Highly accurate tree models derived from terrestrial laser scan data-a method description. Forests 5:1069-1105. https://doi. org/10.3390/f5051069

Hackenberg J, Spiecker H, Calders K, Disney M, Raumonen P (2015) SimpleTree-an efficient open source tool to build tree models from TLS clouds. Forests 6(11):4245-4294

Hakala T, Suomalainen J, Kaasalainen S, Chen Y (2012) Full waveform hyperspectral LiDAR for terrestrial laser scanning. Opt Exp 20(7):7119-7127

Harris NL, Brown S, Hagen SC, Saatchi SS, Petrova S, Salas W, Hansen MC, Potapov PV, Lotsch A (2012) Baseline map of carbon emissions from deforestation in tropical regions. Science 336(6088):1573-1576

Hill TC, Williams M, Bloom AA, Mitchard ET, Ryan CM (2013) Are inventory based and remotely sensed above-ground biomass estimates consistent? PLoS ONE 8(9):e74170

Hopkinson C, Chasmer L, Young-Pow C, Treitz P (2004) Assessing forest metrics with a ground-based scanning lidar. Can J For Res 34:573-583. https://doi.org/10.1139/x03-225

IPCC (2006) Guidelines for national greenhouse gas inventories, Prepared by the national greenhouse gas inventories programme. In: Eggleston HS, Buendia L, Miwa K, Ngara T, Tanabe K (eds) IGES, Tokyo

Jackson T, Shenkin A, Wellpott A, Calders K, Origo N, Disney MI, Burt A, Raumonen P, Gardiner B, Herold M, Fourcaud T, Malhi Y (2019) Finite element analysis of trees in the wind based on terrestrial laser scanning data. Agric For Meteorol 265(15):137-144. https://doi.org/10.1016/j.agrfo rmet.2018.11.014 
Ketterings QM, Coe R, van Noordwijk M, Ambagau Y, Palm CA (2001) Reducing uncertainty in the use of allometric biomass equations for predicting above-ground biomass in mixed secondary forests. Forest Ecol Manag 146:199-209

Krishna Moorthy SM, Calders K, di Porcia e Brugnera M, Schnitzer SA, Verbeeck H (2018) Terrestrial laser scanning to detect liana impact on forest structure. Remote Sens 10(6):810

Le Toan T, Quegan S, Davidson M, Balzter H, Paillou P, Papathanassiou K, Plummer S, Rocca F, Saatchi S, Shugart H, Ulander L (2011) The BIOMASS Mission: mapping global forest biomass to better understand the terrestrial carbon cycle. Remote Sens Environ 115:2850-2860

Lewis SL, Sonké B, Sunderland T, Begne SK, Lopez-Gonzalez G et al (2013) Above- ground biomass and structure of 260 African tropical forests. Philos Trans R Soc Lond B Biol Sci 368:1625. https:// doi.org/10.1098/rstb.2012.0295

Liang X, Hyyppä J, Kaartinen H, Lehtomäki M, Pyörälä J, Pfeifer N, Holopainen M, Brolly G, Francesco P, Hackenberg J, Huang H (2018) International benchmarking of terrestrial laser scanning approaches for forest inventories. ISPRS J Photogr Remote Sens 144:137-179

Lutz JA et al (2018) Global importance of large-diameter trees. Glob Ecol Biogeogr 27(7):849-864. https://doi.org/10.1111/geb.12747

Mascaro J, Litton CM, Hughes RF, Uowolo A, Schnitzer S (2011) Minimizing bias in biomass allometry: model selection and log-transformation of data. Biotropica 43(6):649-653. https://doi.org/10. 1111/j.1744-7429.2011.00798.x

Mermoz S, Réjou-Méchain M, Villard L, Le Toan T, Rossi V, Gourlet-Fleury S (2015) Decrease of L-band SAR backscatter with biomass of dense forests. Remote Sens Environ 159:307-317

Mitchard ETA, Saatchi SS, Baccini A, Asner GP, Goetz SJ, Harris NL, Brown S (2013) Uncertainty in the spatial distribution of tropical forest biomass: a comparison of pan-tropical maps. Carbon Balance Manag. https://doi.org/10.1186/1750-0680-8-10

Mitchard ETA et al (2014) Markedly divergent estimates of Amazon forest carbon density from ground plots and satellites. Global Ecol Biogeogr 23(8):935-946

Molto Q, Rossi V, Blanc L (2013) Error propagation in biomass estimation in tropical forests. Methods Ecol Evol 4:175-183. https://doi.org/10.1111/j.2041-210x.2012.00266.x

Momo Takoudjou S, Ploton P, Sonké B, Hackenberg J, Griffon S, de Coligny F, Kamdem NG, Libalah M, Mofack GI, Le Moguédec G, Pelissiér R, Barbier N (2017) Using terrestrial laser scanning data to estimate large tropical trees biomass and calibrate allometric models: a comparison with traditional destructive approach. Methods Ecol Evol 9:905-916

Momo ST, Libalah MB, Rossi V, Fonton N, Mofack GI, Kamdem NG, Nguetsop VF, Sonké B, Ploton P, Barbier N (2018) Using volume-weighted average wood specific gravity of trees reduces bias in aboveground biomass predictions from forest volume data. For Ecol Manag 424:519-528

Newnham G, Armston J, Muir J, Goodwin N, Tindall D, Culvenor D, Püschel P, Nyström M, Johansen K (2012) Evaluation of terrestrial laser scanners for measuring vegetation structure. CSIRO, Canberra

Newnham GJ, Armston JD, Calders K, Disney MI, Lovell JL, Schaaf CB, Strahler AH, Danson FM (2015) Terrestrial laser scanning for plot scale forest measurement. Current For Rep 1(4):239-251. https://doi.org/10.1007/s40725-015-0025-5

Niklas KJ (1993) Influence of tissue density-specific mechanical properties on the scaling of plant height. Ann Bot 72:173-179. https://doi.org/10.1006/anbo.1993.1096

Noelke N, Fehrmann L, Nengah SJ, Tiryana T, Seidel D, Kleinn C (2015) On the geometry and allometry of big-buttressed trees - a challenge for forest monitoring: new insights from 3D-modeling with terrestrial laser scanning. For-Biogeosci For 8:574. https://doi.org/10.3832/ifor1449-007

Othmani A, Voon LFCLY, Stolz C, Piboule A (2013) Single tree species classification from Terrestrial Laser Scanning data for forest inventory. Pattern Recognit Lett 34:2144-2150

Pan Y, Birdsey RA, Fang J, Houghton R, Kauppi PE et al (2011) A large and persistent carbon sink in the world's forests. Science 333(6405):988-993. https://doi.org/10.1126/science.1201609

Paynter I, Saenz E, Genest D, Peri F, Erb A, Li Z, Wiggin K, Muir J, Raumonen P, Schaaf ES, Strahler A, Schaaf C (2016) Observing ecosystems with lightweight rapid-scanning terrestrial lidar scanners. Remote Sens Ecol Conserv 2(4):174-189. https://doi.org/10.1002/rse2.26

Paynter I, Genest D, Saenz E, Peri F, Li Z, Strahler A, Schaaf C (2018) Quality assessment of terrestrial laser scanner ecosystem observations using pulse trajectories. IEEE Trans Geosci Remote Sens. https://doi.org/10.1109/TGRS.2018.2836947

Phillips OL, Baker T, Feldspauch T Brienen RJW (2002) Field manual for plot establishment and remeasurement (RAINFOR). Amazon Forest Inventory Network, Sixth Framework Programme (2002-2006)

Preuksakarn C (2012) Reconstructing plant architecture from 3D laser scanner data (Doctoral dissertation, Université Montpellier II-Sciences et Techniques du Languedoc) 
Raumonen P, Kaasalainen M, Åkerblom M, Kaasalainen S, Kaartinen H, Vastaranta M, Holopainen M, Disney MI, Lewis P (2013) Comprehensive quantitative tree models from terrestrial laser scanner data. Remote Sens 5(2):491-520. https://doi.org/10.3390/rs5020491

Raumonen P, Åkerblom M, Kaasalainen M, Casella E, Calders K, Murphy S (2015) Massive-scale tree modelling from TLS data. In: ISPRS annals of photogrammetry, remote sensing and spatial information sciences, p 2

Réjou-Méchain M, Tanguy A, Piponiot C, Châvé J, Hérault B (2017) biomass: an r package for estimating above-ground biomass and its uncertainty in tropical forests. Methods Ecol Evol 8(9):11631167. https://doi.org/10.1111/2041-210X.12753

Saatchi S et al (2011) Benchmark map of forest carbon stocks in tropical regions across three continents. Proc Natl Acad Sci 108(24):9899-9904

Sheil D, Eastaugh CS, Vlam M, Zuidema PA, Groenendijk P, der Sleen P, Jay A, Vanclay J (2016) Does biomass growth increase in the largest trees? Flaws, fallacies, and alternative analyses. Funct Ecol 31(3):568-581

Sileshi GW (2014) A critical review of forest biomass estimation models, common mistakes and corrective measures. For Ecol Manag 329:237-254

Slik JWF, Arroyo-Rodriguez V, Aiba S-I, Alvarez-Loayza P, Alves LF et al (2015) An estimate of the number of tropical tree species. Proc Natl Acad Sci 112(24):7472. https://doi.org/10.1073/pnas.14231 47112

Stovall AE, Shugart HH (2018) Improved biomass calibration and validation with terrestrial LiDAR: implications for future LiDAR and SAR missions. IEEE J Sel Top Appl Earth Observ Remote Sens 99:1-11

Stovall AE, Vorster AG, Anderson RS, Evangelista PH, Shugart HH (2017) Non-destructive aboveground biomass estimation of coniferous trees using terrestrial LiDAR. Remote Sens Environ 200:31-42. https ://doi.org/10.1016/j.rse.2017.08.013

Stovall AE, Anderson-Teixeira KJ, Shugart HH (2018) Assessing terrestrial laser scanning for developing non-destructive biomass allometry. For Ecol Manage 427:217-229

Swenson NG, Enquist BJ (2007) Ecological and evolutionary determinants of a key plant functional trait: wood density and its community-wide variation across latitude and elevation. Am J Bot 94:451-459

Tang S (2017) Quantifying Differences in Forest Structures with Quantitative Structure Models from TLS Data, UCL M.Sc. thesis (unpublished)

Ter Steege H, Pitman NCA, Sabatier D, Baraloto C, Salomaõ RP et al (2013) Hyperdominance in the amazonian tree flora. Science 342:6156. https://doi.org/10.1126/science.1243092

Ter-Mikaelian MT, Korzukin MD (1997) Biomass equations for sixty-five North American tree species. For Ecol Manag 97:1-24

Trochta J, Krůček M, Vrška T, Král K (2017) 3D Forest: an application for descriptions of three-dimensional forest structures using terrestrial LiDAR. PLoS ONE 12(5):0176871. https://doi.org/10.1371/ journal.pone.0176871

USFS (2019) US Forestry Service Forest Inventory and Analysis Design, https://www.fia.fs.fed.us/library/ fact-sheets/data-collections/Sampling\%20and\%20Plot\%20Design.pdf. Accessed Feb 2019

Widlowski JL, Pinty B, Lopatka M, Atzberger C, Buzica D, Chelle M, Disney MI, Gastellu-Etchegorry JP, Gerboles M, Gobron N, Grau E, Huang H, Kallel A, Kobayashi H, Lewis P, Schlerf M, Stuckens J, Qin W, Xie D (2013) The 4th Radiation Transfer Model Intercomparison (RAMI-IV): using ISO standards to evaluate model proficiency. JGR Atmos 118:6869-6890. https://doi.org/10.1002/jgrd.50497

Wilkes P, Lau A, Disney MI, Calders K, Burt A, de Tanago Gonzalez, Menaca J, Bartholomeus H, Brede B, Herold M (2017) Data acquisition considerations for terrestrial laser scanning of forest plots. Remote Sens Environ 196:140-153. https://doi.org/10.1016/j.rse.2017.04.030

Yan D-M, Wintz J, Mourrain B, Wang W, Boudon F, Godin C (2009) Efficient and robust reconstruction of botanical branching structure from laser scanned points. In: 11th IEEE international conference on computer-aided design and computer graphics (CAD/Graphics 2009)

Yun T, An F, Li W, Sun Y, Cao L, Xue L (2016) A novel approach for retrieving tree leaf area from groundbased LiDAR. Remote Sens 8(11):942

Zanne AE et al (2009) Data from: towards a worldwide wood economics spectrum. Dryad Digit Repos. https://doi.org/10.5061/dryad.234

Publisher's Note Springer Nature remains neutral with regard to jurisdictional claims in published maps and institutional affiliations. 


\section{Affiliations}

M. Disney ${ }^{1,2} \mathbb{D} \cdot$ A. Burt ${ }^{1} \cdot$ K. Calders ${ }^{3} \cdot$ C. Schaaf $^{4} \cdot$ A. Stovall $^{5}$

1 Department of Geography, UCL, Gower Street, London WC1E 6BT, UK

2 NERC National Centre for Earth Observation (NCEO), London WC1E 6BT, UK

3 CAVElab - Computational and Applied Vegetation Ecology, Department of Environment, Ghent University, 9000 Ghent, Belgium

4 School for the Environment, University of Massachusetts Boston, 100 Morrissey Blvd, Boston, MA 02125, USA

5 Department of Environmental Sciences, University of Virginia, Charlottesville, VA 22903, USA 